\title{
Physical Disability and Sexuality, Some History and Some Findings
}

\author{
Stine Hellum Braathen, Mark T. Carew, Mussa Chiwaula, \\ and Poul Robleder
}

\section{INTRODUCTION}

How does a man or a woman who is paralysed and uses a wheelchair have sex? Do people who have physical disabilities have different sexual needs and desires than people without disabilities? Is sex and sexuality

S. H. Braathen $(\bowtie)$

Department of Health Research, SINTEF Digital, Oslo, Norway

e-mail: stine.H.Braathen@sintef.no

M. T. Carew

UCL International Disability Research Centre, Department of Epidemiology and Public Health, University College London, London, UK

e-mail: m.carew@ucl.ac.uk

M. Chiwaula

Southern African Federation of the Disabled, Gaborone, Botswana

e-mail: mchiwaula@safod.net

P. Rohleder

Department of Psychosocial and Psychoanalytic Studies, University of Essex, Colchester, UK

e-mail: p.rohleder@essex.ac.uk

(C) The Author(s) 2021

X. Hunt et al. (eds.), Physical Disability and Sexuality, https://doi.org/10.1007/978-3-030-55567-2_2 
a different experience when your embodiment changes following an acquired disability? Why are there so few "sex symbols" in popular culture who are people with physical disabilities?

In this chapter we look at some of the myths and assumptions that many people without disabilities hold about the sexuality of people with physical disabilities. We look at what societal attitudes there may be concerning sexuality and disability, and what this means for people with physical disabilities and their sexual lives. We present some of the findings from the survey and interview study mentioned in Chapter 1, and some of the photos and personal stories of project participants.

\section{Disability and Sexuality: Myths AND Misconceptions}

\section{The Assumption of Asexuality}

People in society, including health professionals, hold many shared views about the sexual lives of others. Many people hold ideas about what sorts of sexual beings other people are, whether they can or ought to have sexual relationships, and with whom. Research and anecdotal reports suggest that people without disability hold many incorrect assumptions about the sexual lives of people with disabilities (Hunt et al., 2017a, b, 2018). For example, people without disability may see a person who uses a wheelchair as incapable of having sex, and so they are assumed to be asexual. In disability studies, this has been written about as the "myth of asexuality" (Milligan \& Neufeldt), and seems to be quite a prevalent assumption that people without disability have about people with physical disabilities (Carew, Braathen, Swartz, Hunt, \& Rohleder, 2017; Rohleder, Braathen, \& Carew, 2018). Asexuality itself is not a mythsome people identify as asexual-but for people with physical disabilities, they are merely assumed by others to be non-sexual, and even to have little interest in sex and intimacy, when for the vast majority of people with physical disabilities this is not true.

These assumptions by people without disability also include stigmatising and even oppressive attitudes and views about physical disability itself. As we saw in the first chapter, one can understand what is meant by "disability" not only in terms of bodily or psychological impairment, but more importantly to be a result of societal exclusion of people with various impairments (Goodley, 2016). One obvious example of how this happens is in terms of widely held misperceptions about the abilities of 
people with physical disabilities, for instance that being in a relationship with someone who has a physical disability means having to take care of them (Marini, Chan, Feist, \& Flores-Torres, 2011).

People with physical disabilities are often subject to stigma and may be seen as possessing characteristics that are undesirable to others (Hunt et al., 2018). As such, people with physical disabilities are often on the receiving end of patronising behaviour and pity from others, especially where the cause of the disabling characteristic is perceived as uncontrollable (e.g. as the outcome of an accident rather than an addiction) (Goffman, 1997).

In the introduction, we spoke about impairments and disability, and the difference between the two. Impairments themselves are often seen as abnormalities and defects that need to be prevented and avoided. In the past this often resulted in the sterilisation of people with disabilities, particularly women. Men and women with physical disabilities were sterilised so as to prevent them from having children with physical disabilities, and in many cases in the past, this sterilisation was forced (Park \& Radford, 1998; Tilley et al., 2012). Scholars refer to this as "sterilisation abuse" (Roy, 2010). Sterilisation of people with disabilities is not just a thing of the past; it is still practiced today, but more likely in cases where the person has an intellectual disability, rather than a physical disability.

However, even if sterilisation is not used today as a way of controlling the sexual and reproductive lives of people with physical disabilities, there are still strongly held views in society about whether people with physical disabilities can and should have children, and so they may be viewed as asexual, not just because they are assumed as incapable of having sex, but actually because some individuals without disabilities feel that they should not have sex, because they cannot or should not have children (Cuskelly \& Gilmore, 2007; Gilmore \& Chambers, 2010). The story of some of the participants who share narratives in this book describe experiences of being viewed as non-sexual, and Pride (see Chapter 4 ) and also notes that others doubted whether she should or could be in sexual relationships, marry, and have children. Vic, in Chapter 9, discusses others' attitudes to his wife's pregnancy, which also reflects this dynamic.

In recent decades, however, things have improved for people with physical disabilities in this area. Some research suggests that attitudes towards the sexuality of people with physical disabilities are nuanced and many may be positive, too (Hunt et al., 2018). As mentioned in Chapter 1, international policies and guidelines, like the United Nations 
Convention on the Rights of People with Disabilities have ensured that the rights of people with disabilities are brought to attention (United Nations, 2006). Characters with disabilities, including physical disabilities, appear more in television programmes and movies in a broader array of roles, and are not only depicted narrowly as they were in the past (Milligan \& Neufeldt, 2001). The improvement of attitudes towards physical disability will also be helped by continuing efforts from governments and businesses to make all aspects of society accessible to people with disabilities.

Evidence from our survey suggests that simply having the opportunity to interact with people who have physical disabilities is likely to combat negative attitudes towards them (Carew et al., 2019), including if this contact is virtual in nature (e.g. watching people with disabilities through media like the Paralympics; Carew et al., 2019). However, there is also evidence to suggest that this is primarily the case when the nature of the interaction is positive. If the nature of the interaction is negative, contact can, in fact, emphasise and increase stigmatising attitudes towards people with physical disabilities (Paluck et al., 2019). Despite the gradual positive societal change in past decades, many assumptions and stereotypes about disability still exist.

We have talked here about the myth of asexuality of people with physical disabilities, and of course we do not mean that all people without disability think this of people with physical disabilities. The question is: How prevalent is this myth?

In the research that was carried out in South Africa which informed the writing of this book (see description in Chapter 1), part of the work we did was a survey study, conducted in order to measure the views held by South Africans without disability about the sexuality of people with disabilities. Of the total 1990 respondents to the survey, 1865 people identified themselves as being without disability, and for analyses concerning people without disability's attitudes, we examined their responses. Concerning their views about the sexuality of people with physical disabilities, the survey revealed some clear differences between what views were held towards people with physical disabilities when compared to views held towards people without disability. The survey contained questions about respondents' beliefs about the sexuality and sexual rights of people with physical disabilities and the (general) population who are without disability. Respondents were asked to indicate what percentage of people with physical disabilities the following statements applied to: 
Table 2.1 Percentage of (1) people with physical disabilities and (2) the general population to whom the following statements apply

\begin{tabular}{lcc}
\hline & People with disabilities (\%) & General population (\%) \\
\hline $\begin{array}{l}\text { Capable of expressing sexuality } \\
\text { Sexuality is a basic human need }\end{array}$ & 61.47 & 72.49 \\
$\begin{array}{l}\text { Should be allowed to have } \\
\text { children }\end{array}$ & 66.21 & 73.03 \\
$\begin{array}{l}\text { Benefit from sexual health care } \\
\text { services }\end{array}$ & 74.22 & 74.38 \\
$\begin{array}{l}\text { Benefit from reproductive health } \\
\text { care services }\end{array}$ & 61.80 & 70.25 \\
$\begin{array}{l}\text { Benefit from sexual education } \\
\text { services }\end{array}$ & 59.04 & 69.60 \\
\hline
\end{tabular}

1. The percentage of people with physical disabilities that are capable of expressing sexuality.

2. The percentage of people with physical disabilities for whom expressing sexuality is a basic human need.

3. The percentage of people who have physical disabilities who should be allowed to have children.

4. The percentage of people with physical disabilities who benefit from sexual health care services.

5. The percentage of people with physical disabilities who benefit from reproductive health care services.

6. The percentage of persons with physical disabilities who benefit from sexual education services.

They were then asked to indicate the percentage of the general population these same questions applied to. The results are in Table 2.1, which is reproduced from an article which we published in the journal Reproductive Health Matters. ${ }^{1}$

${ }^{1}$ The journal article in which this figure was published, Hunt, X., Carew, M. T., Braathen, S. H., Swartz, L., Chiwaula, M., \& Rohleder, P. (2017). The sexual and reproductive rights and benefit derived from sexual and reproductive health services of people with physical disabilities in South Africa: beliefs of non-disabled people. Reproductive Health Matters, 25(50), 66-79, is an open-access article, and so no permission was required for the reproduction of this figure. 
Table 2.2 Percentage of (1) people with physical disabilities, $(2)$ the general population, who identify as...

\begin{tabular}{lcc}
\hline $\begin{array}{l}\text { Percentage who identify } \\
\text { as }\end{array}$ & $\begin{array}{c}\text { People with } \\
\text { disabilities }\end{array}$ & $\begin{array}{c}\text { General } \\
\text { population }\end{array}$ \\
\hline Asexual & 29.97 & 25.23 \\
Bisexual & 21.21 & 27.69 \\
Gay or lesbian & 23.12 & 32.12 \\
Heterosexual & 61.58 & 65.20 \\
\hline
\end{tabular}

From this table we can see that respondents without disability, on average, felt that these statements about sexual rights and sexuality applied less to people with physical disabilities than to the general population without disability. So, for example, respondents, on average, felt that $61.47 \%$ of people with physical disabilities are capable of expressing sexuality compared to $72.49 \%$ of the general population without disability being seen as capable of expressing their sexuality. When we did a statistical analysis of these responses as a group measure, we found that these percentages were mostly significantly different (Hunt et al., 2017a). This means that in our sample, people with physical disabilities were viewed as less sexual and having fewer sexual health needs and rights than people without disability, though this does not mean that this pattern necessarily exists elsewhere (e.g. in the entire South African population).

We also asked respondents to indicate what percentage of people with and without physical disabilities identify as asexual, gay or lesbian, bisexual or heterosexual. The results are presented in Table 2.2.

The important thing to note in the table above is that respondents assume more people with physical disabilities to be asexual than people without disability. Furthermore, fewer people with physical disabilities are assumed to be gay or lesbian, heterosexual or bisexual than people without disability. These are assumptions that respondents without disability in our sample have; that does not mean that they are truths. What these findings show, however, is that people without disability tend to assume that physical disability somehow negates sexuality.

\section{Stereotypes About Disability}

Related to the assumptions about sexuality discussed above, many people without disability hold various stereotypes about people with physical disabilities. Stereotypes are sets of characteristics and personal qualities 
that are seen as shared by members of a social group and consequently attributed to individuals based on their perceived membership of that group (Brown, 2011). For example, a commonly held stereotype of British people is that they have what many refer to as "a stiff upper lip". This stereotype assumes this characteristic of British people, regardless of whether it is accurate.

People with physical disabilities have often been the subject of a number of problematic stereotypes, particularly by portrayals of disability in the media (e.g. films, books, TV shows; Rohleder et al., 2018). These portrayals include where a person with physical disability is portrayed as a kind of "freak" or as some kind of medical oddity (Condrau, 2007; Garland-Thomson, 2009). Popular disability stereotypes are not always negative at face value. Sometimes they can be well meaning, as in cases where people with disabilities are portrayed as inspirational people who have overcome hardships. These portrayals are sometimes referred to as the "supercrip" (Grue, 2016; Shakespeare, 1994)—the heroic, brave person with disability who has achieved greatness, or achieved something that is to be admired. However, the damage arises when stereotypeseven ones which could be seen in a positive light sometimes-are used at the expense of 'normal' representation. Over and over again, people with physical disabilities are portrayed in limited and limiting ways, rather than as real, complex characters. Common stereotypes are that people with physical disabilities are seen as weak, helpless and incompetent (Crawford \& Ostrove, 2008), or that they are not "real" or "whole" men or women (Fine \& Asch, 2018; Nario-Redmond, 2010), or as gendered as men and women without disability.

If you, reader, were asked to state three words or traits that come to mind when thinking about a man or woman with a physical disability, what would come to mind? Obviously, everyone is different and has had a different experience with people with physical disabilities.

Some of you may have a friend, partner or family member with a disability. You may even be a person with a disability yourself. So, the words or traits that come to mind may accurately portray the person that you know. But if you do not really know someone with a disability and you think in general terms, where do your ideas come from? What shaped them? In our survey study (see Chapter 1) we wanted to find out what some of the stereotypes are that people without disability have about people with disabilities in South Africa. We asked respondents to state three traits or words that came to mind when (a) thinking of a woman with a physical disability, and (b) a man with a physical disability. 


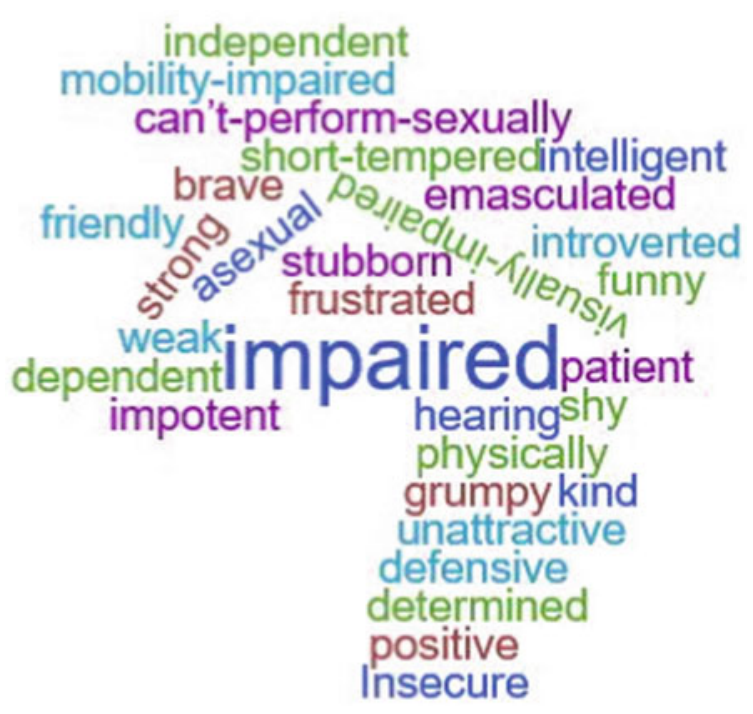

Fig. 2.1 Stereotypes for men (Author's own)

What we found was striking, and similar to what has been found by another research study conducted in the United States of America (Crawford \& Ostrove, 2008). In our survey, respondents without disability described men with physical disabilities most often in terms such as strong, funny, insecure, shy and determined. We have reported these findings extensively in an article in Disability or Society. ${ }^{2}$ Similarly, women with physical disabilities were seen as strong, insecure, shy, kind, and friendly. Below are two word clouds depicting the most common words used for men and women with physical disabilities. What do you find interesting about what you see here? Were your words included in these word clouds? (Figs. 2.1 and 2.2).

There are many ways of interpreting what these words mean, but what we can see is some similarity in words used to describe both men and women (Hunt et al., 2018). We see stereotypes depicting both men and women with physical disabilities as withdrawn and dependent, Supercrips, nice guys/girls, angry/irritable and aloof, and asexual. These findings are

${ }^{2}$ The findings from this work were first reported in a journal article: Hunt et al., (2018). Withdrawn, strong, kind, but de-gendered: non-disabled South Africans' stereotypes concerning persons with physical disabilities. Disability \& Society, 1-22. We have requested permissions to recount our findings here. The request is Taylor \& Francis order number 4604730263839 . 


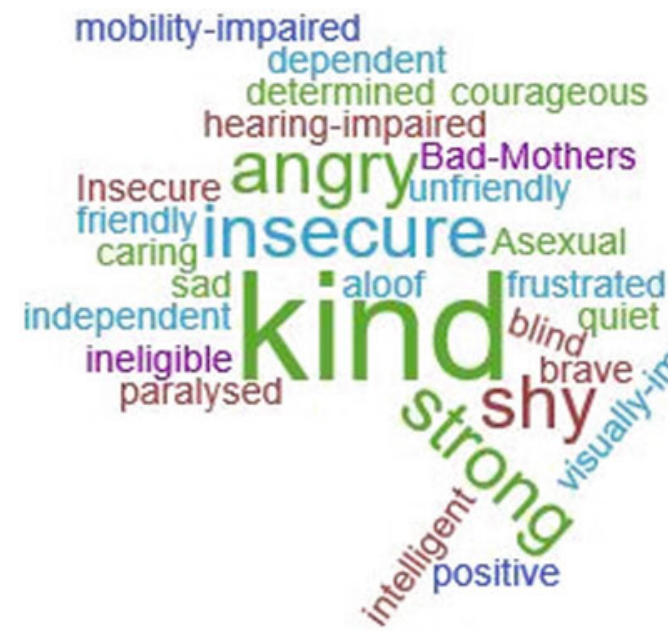

Fig. 2.2 Stereotypes for women (Author's own)

interesting not only because they reveal the content of stereotypes about people with physical disabilities, but also because they are so similar across genders: usually, stereotypes for men and women differ along a gendered line, but for people with physical disabilities, many of the stereotypes were the same, regardless of whether the target of the stereotype was male or female. This seems to suggest that people with physical disabilities are seen as less gendered than people without disability, evidence also of the desexualisation of people with disabilities (Hunt et al., 2018). Overall, the stereotypes cited by our survey respondents seem to reflect genderneutral disability stereotypes, rather than gender stereotypes. This seems to provide evidence that physical disability seems more salient than gender in terms seem to reflect gender-neutral disability stereotypes, rather than gender stereotypes. This seems to provide evidence that physical disability seems more salient than gender in terms of salience in stereotype activation: people without disability are likely to stereotype people with physical disabilities according to their disability status prior to their gender (for a similar conclusion see Vilchinsky, Werner, and Findler [2010]). Thus, people may see the disability first and foremost before seeing the man or woman. This is also a point made by many participants interviewed in our qualitative photovoice study, for example Bongani (see below). 


\section{What People with Physical Disabilities Experience}

In our qualitative interviews with people with physical disabilities (see description of study in Chapter 1), many spoke about the various stereotypes and assumptions they faced from people without disability. For example, Mandla, a man who had acquired a physical disability as an adult in 2010, talked about how women tended to regard him as incapable of having sex, and thus not a "real" sexual partner:

Most of the ladies like to tease me and they say "come, I want to marry you". And then they say, "if I marry you, how are you going to satisfy me sex-wise?" I said, "that's the problem with you people, when you look at people with spinal cord injuries, people with physical disabilities, you still have that mindset of saying that they can't have sex, they can't do this or they can't do that. That is your big mistake. We can have sex. We can live a normal life like everyone. So that thing must come out of your mind."

For some, these messages were received from childhood, with family members regarding the child with a physical disability as not suitable for future marriage and intimate relationships. In the next chapter, Martha's story speaks about this. Similarly, Khadija, a middle-aged, woman who was born with disability spoke about how her family always viewed her as asexual, and not able to get married and have intimate relationships, and expectations which she said that they, as a traditional Muslim family, had for other girls:

For the family it's like, I'll never get married... for them it was just a friend. No idea about the wishes or dreams of this young woman to one day get married, because it's impossible.

Of course, having a physical disability does mean that there may be some difficulties with sexual functioning. Depending on the type of physical disability, a person may experience a lack of physical sensation that allows them to enjoy penetrative sex or be able to perform sexually in that way. For example, men with paralysis may not be able to get an erection, and may require medical aids to help with sexual performance. However, from our study it seemed a bigger barrier was the attitudes of many people without disability who assumed that sex is impossible for people with disabilities. For example, Sifiso, a 28 -year-old man, who acquired a disability at the age of 23 , says: 
...being disabled means that I can still do everything with the help of medicine, more especially when it comes to a sexual life. So, with the help of medicine I can be sexually active; with the help of medicine I can get babies. But other people, because they don't know, but only because they don't know, they think that, ah, he can't have sex. That's the first question in our society, they don't know what happens to a person who is using a wheelchair. They'll just assume that you have a waist problem and you can't be sexually active.

These assumptions, and being excluded in this way, can have a big impact on the psychological well-being of some people with physical disabilities. Furthermore, sexuality is often thought of as penetrative sex, but sexuality is much more than that. There are various ways of experiencing and expressing sexuality, including other forms of physical and emotional intimacy and touch, and companionship. For instance, the story of Pride and her photograph below tells about her experience of loneliness as a result of her sexuality being questioned by others.

\section{Pride's Story}

Pride is a 42 -year-old woman who has lived for a long time with a physical disability as a result of polio. In her interview, she spoke about how her peers at school would dismiss her and tease her as being someone who could not have a boyfriend:

I also wanted to be loved, to belong, to be appreciated. But people couldn't understand. I remember, the first time I was at high school now, and then the boys would follow me. And then I was with this boy and this boy heard that thing about me, and then the other one would pass and say, "oh, I don't think that disabled people can have boyfriends." But that would come to my heart also.

She went on to say how she experienced that men would want to try and have sex with her just to see whether indeed she could have sex. She said:

....along the way some of the guys would just say, "no, I'm not interested in this one, I just want to test if she is sexually active or if she can do that." 
As a result she felt that men would use her as a "test" just to see if she was capable of having sex or not. This left her feeling very vulnerable to abuse and exploitation, and she has decided to live a single life. However, this has meant that she is lonely. She explained:

I'm still alone now. I don't have a child. I don't have a boyfriend. I'm just by myself. I don't want to be hurt now. I had many disappointments, so now, no, it's enough. I've had enough. That's why I told myself, no, if God wants me to be like this, then it's fine. I had dreams as a woman. I also wanted to get married and have children and have my own house. I wanted to be like that, but it never happened. I have my own car and my own house. I only have my house now and the car, that's all. There's no one next to me. There's no shoulder to cry on. You need company at times. But now I don't want someone who is going to come to take advantage of me at the same time.

What we see in Pride's story is that sexuality to her is much more about love and companionship than it is about the act of sex alone. Yet, because for others sex acts are a point of entry into, or something which comes part and parcel with, reomantic relationships, and sex is something Pride has negative experiences of, she struggles to develop a real, meaningful intimate relationship and express her sexuality in a manner which works for her.

\section{Excluded from Sex Education}

We learn about sex and sexuality in our childhood and adolescent years. Typically, we are taught about sex and sexual health at school. Maybe our parents teach some of us about sex or give us a book to read about it. These days we also learn about sex and sexuality (positive and negative things) on the internet. For the most part, society understands that educating adolescents about sex, relationships and sexual health is important and necessary. When it comes to children and adolescents with disabilities, however, people's views about this differ. A lot of research from all over the world has consistently shown that young people with disabilities receive less sexual health education than their peers without disability (Nario-Redmond, 2010).

There are various reasons for this. Research has shown that in countries throughout the world, people with disabilities receive less education overall than the general population. WHO \& The World Bank (2011, p. 206) has stated that: 
In general, children with disabilities are less likely to start school and have lower rates of staying and being promoted in school.

This pattern has been found for both low-income and high-income countries, and females with disabilities are most disadvantaged in terms of their access to education. Reasons why children with disabilities receive lower levels of education has a lot to do with society's understandings about the capabilities and productivity of people with disabilities. People with disabilities, including physical disabilities, may be regarded as less capable of working and of being productive in employment, and so their education is not prioritised. Research has shown that in poorer countries, where the chances for employment are few, parents may choose to focus their resources on educating their children without disability, who will have a better chance of getting work, than their child with physical disability (WHO \& The World Bank, 2011).

Another reason may be that educating a child with a physical disability requires more resources and is thus more expensive than educating a child who does not have a disability (Groce, 2003), and so families may not be able to meet these costs. Further, in some countries, such educational resources are not adequately provided by governments. Schools are also typically built with children without disability primarily in mind, and so many schools are inaccessible to children with physical disabilities. In mainstream schools and classes, children with disabilities may often be regarded as a disruption to the learning of other children.

Not receiving adequate levels of education consequently reduces the chances of children and adolescents with disabilities receiving sex education in schools. Nevertheless, even where children and adolescents with physical disabilities are at school, they are still less likely to receive sex education than children and adolescents without disability. This may often have to do with the assumption held by parents and teachers that young people with physical disabilities are asexual, or are unlikely to get married or have relationships, and thus do not need sex education (Wolfe, 1997). Some parents and teachers may acknowledge that young people with physical disabilities can be sexual, but are afraid of their child becoming sexual or having sex, and so the topic of sex education is best avoided. Two South African studies have found that educators lacked the knowledge and-particularly-confidence to successfully teach sexuality education to adolescents with disabilities (Chirawu et al., 2014; de Reus et al., 2015). This increased the students' vulnerability to HIV (de Reus et al., 2015). 
Further, while poorly delivering sex education to youth with physical disabilities increases risk and robs young people sex education of knowledge about safe sexual practices, and sexual and reproductive health, it also limits opportunities for the development of sexual confidence and self-esteem. Sex education is also important in terms of providing young people with an understanding about their own bodies, and giving them the knowledge and skills needed to make their own informed choices about sex and relationships, what the social norms are about sexuality and relationships, and to recognise abusive or exploitative sexual behaviours. Young people with disabilities are thus often excluded from these educational needs. In South Africa, the failure of sex education to provide for children with disabilities has been cited as increasing these students' vulnerability to HIV and other negative sexual health outcomes (de Reus et al., 2015).

Not only are people with physical disabilities often excluded from sex education, but disability as a topic is typically not included in general sex education. The emphasis tends to be on the "normative" able body. Thus, young people with disabilities may not always receive sex education which is specifically relevant to their own needs (WHO \& The World Bank (2011), and young people without disability do not typically get a chance to consider disability as an experience in relation to sexuality within the sex education they receive. This separation may play a role in how people without disability, and people with physical disabilities, consider the possibilities of having relationships with each other.

\section{Sexual Violence and Abuse}

In Pride's story above, she refers to her fear of being taken "advantage of", sexually. Sadly, there is reality to this for people with physical disabilities. Research from around the world has indicated that people with disabilities, particularly women and children with physical disabilities, are more likely to be victims of abuse. By abuse, we refer to a variety of forms of maltreatment, including sexual abuse, physical abuse, emotional abuse, coercion, neglect, deprivation and abandonment (Seidel et al., 2014). Sexual abuse most often refers to rape, but also includes other forms of coercive sexual acts, such as unwanted touching or kissing, forced penetration, sexual exploitation, sexual harassment and unwanted exposure to sexual acts or materials (Hassouneh-Phillips \& McNeff, 2005). 
People with physical disabilities are vulnerable to sexual abuse both at home and outside of home. We use the term "vulnerable" here, but it is important to state that this does not mean that the "fault" or the "problem" lies in the person with a physical disability. Many people with physical disabilities may not feel or regard themselves as vulnerable people. Perpetrators, however, may perceive people with disabilities as targets, because they may not be able to defend themselves, or perpetrators may think they might get away with their acts more easily. People with more severe disabilities may require assistance with dressing, toileting and personal care, and so may be vulnerable to the unwanted touch of carers they may be dependent on. Tas's story below is not one of abuse, but he speaks here about how he is dependent on others for intimate care and assistance and this requires a great deal of trust in carers. For Tas, this largely a positive experience. However, for many women with physical disabilities, this same reliance on carers comes at th ecost of vulnerabilitiy to maltreatment.

\section{TAs's STORY}

Tas is a man in his early 30s who acquired a disability at the age of 18. He spoke about the importance for him of being well-groomed and well-dressed to feel good within himself and feel attractive to women. $\mathrm{He}$ provides here a photograph of himself being shaven by a carer (Image 2.1).

Commenting on the photograph, he says:

They are busy shaving me here. I believe that we as men should also be in charge of how we look, grooming ourselves, cutting our nails and being neat at all times. So, the photograph was a photograph of while they were busy shaving me. I always like to be cleanly-shaven. I believe that hygiene is something very important for me. Because like I said, we have to go the extra mile because there's such a lot of things that are already against us as people with disabilities. And I also need to shave a lot because when I kiss my girlfriend she always complains about my beard and stuff like that. So, I can't do it myself. I usually have to ask people to shave me and to groom me and stuff like that. To do my facial hair is no problem, but I 


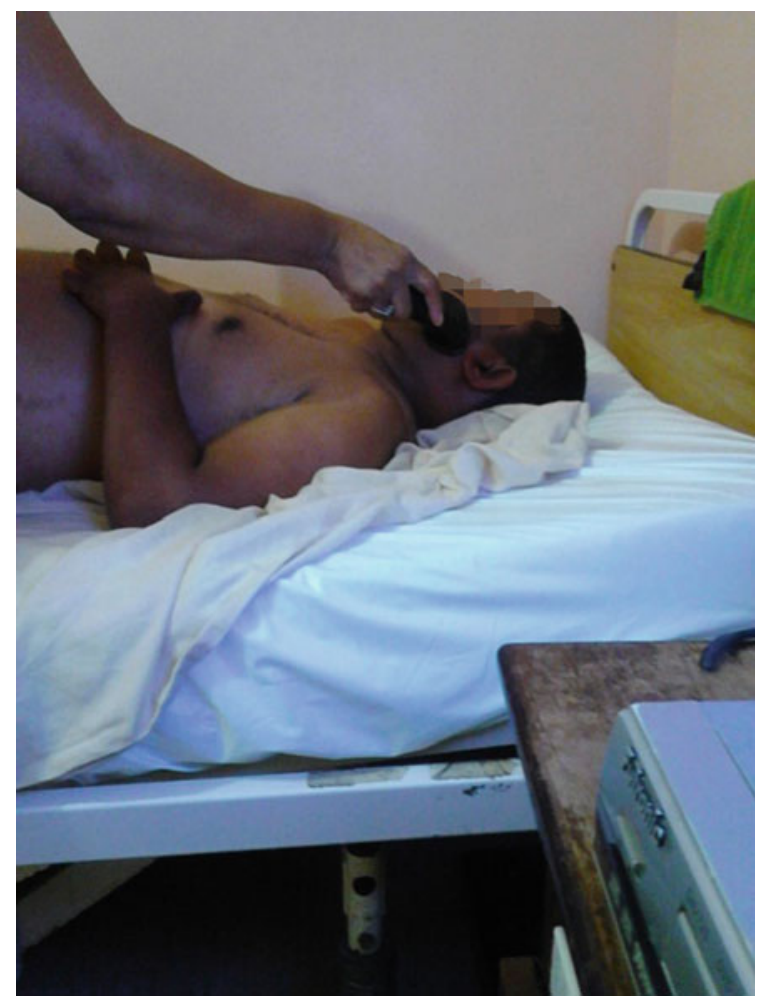

Image 2.1 Grooming (Photo by Tas)

sometimes have difficulty asking people to shave my pubic hair. Okay, my armpit hair is still all right. It's mostly male nurses who work with us and it feels uncomfortable to actually ask a male nurse to shave your pubic hair or whatever. It's sometimes a tight situation because you don't know what position you put that male nurse in and what mindset he has or whatever. So, my facial hair and the hair under my armpits is okay. I like to be clean-shaven. Even with females at times, the boldness isn't always there. You need to have like a special relationship with the nurse to ask them to shave you there. Sometimes it is very difficult because you're letting people into a very personal space of yourself also. You know, sometimes what makes it really difficult is that you don't have any control over your body parts anymore. So, at times you will get an erection, which is quite unpleasant. I don't know why, but sometimes we still get an involuntary 
erection. That is also one of the things that we need to...you always need to have an open relationship with that person, so you need to talk about a lot of things that put you in tricky situations. People can think that you are a pervert or you're flirting with them. They wouldn't want to work with you or whatever. Or you think about things that they will go out and tell someone else about: I was shaving this guy now and he got an erection. So, we've got a lot of explaining to do and we've got a lot of things to do. Sometimes it's really difficult to get to a relationship where we can really trust people to talk all these things about themselves. It's really someone special that has walked a while with you and spent a lot of time with you.

\section{Experiences of Dating and Relationships}

Assumptions that people without disability may have about the sexuality of people with physical disabilities, and ideas about attractiveness and the body, make dating and relationships a potentially difficult experience for people with physical disabilities. Where a person with physical disability lives makes a difference. The issue of freedom of movement is key, and thus being within accessible environments with access to transportation helps the development of romantic relationships, as naturally it allows people with disabilities to engage in the full range of activities people without disability do (e.g. restaurants, cinema). In low- and middleincome countries, like South Africa, economic barriers and a dearth of free services to facilitate access, may make it all the more different for people with physical disabilities to freely engage in dating.

Another important factor in determining people with physical disability's capacity to date, is whether they may live in their own home or are residing in care. It may be the case that a young person with physical disability attends a "special school" or lives in residential care. People with physical disabilities who live in institutions typically do not have many opportunities to socialise with their peers without disability, to date and have relationships. The story of Bongani, a young man, in Chapter 7 , includes his reflecting on what it meant for him to be an adolescent exploring his sexuality in a so-called special school.

Research from various parts of the world has shown that people without disability are sometimes reluctant to date or become romantically involved with someone with a physical disability, because they worry that it may be too awkward to socially interact, or the person with physical disability may require too much caregiving, or because they perceive 
people with physical disabilities as incompetent and dependent (MuellerJohnson et al., 2014). Research has also shown that people without disability may have stereotypical views of people with physical disabilities as "weak" or "unattractive" (Fiske et al., 2002; Marini et al., 2011; Marini et al., 2013). Because of these assumptions and stereotypes, many people without disability report never having been on a date with someone who has a disability. For instance, a survey by a British disability charity found that just $5 \%$ of people without disability who responded to the survey had ever been on a date with a person who has a disability (Nario-Redmond, 2010).

In our survey study, discussed above, we also asked respondents to complete a story which involved a possible dating scenario between a person without disability and a person with a disability. The findings, report in the journal Culture, Health and Sexuality, ${ }^{3}$ reveal largely negative attitudes of people without disability, to the idea of dating people with physical disabilities (Hunt et al., 2018). Respondents without disability perceived numerous barriers to dating a person with a physical disability, including that they thought the relationship would be socially stigmatised (Hunt et al., 2018). They also expressed anxiety and voiced concerns about the burden of care they believed such a relationship would place upon them; they thought that dating a person with a physical disability would be a lot of work. However, there was evidence to suggest that some people without disability held positive attitudes, and a few respondents were open to dating a person with physical disabilities (Hunt et al., 2018).

When it comes to meeting people, the participants that we interviewed in the part of our study with people with disabilities, often spoke about how they felt that others would see their disability first, and the rest of who they are as a person, second. Others would comment on the wheelchair or their disability, making them feel like they, as a whole person, were not fully seen. As a consequence, they felt that potential romantic partners often did not give them a fair chance to get to know

${ }^{3}$ The paper which originally reported these findings is, Hunt, X., Swartz, L., Carew, M. T., Braathen, S. H., Chiwaula, M., \& Rohleder, P. (2018). Dating persons with physical disabilities: The perceptions of South Africans without disabilities. Culture, Health \& Sexuality, 20(2), 141-155. We asked for permission from the journal to refer to the findings contained in the paper, here. However, our analysis of dating beliefs uncovered in our study is detailed in that paper, and if you are interested about this topic, the paper will provide more detail. The request for permissions is Taylor \& Francis order number 4594730091431 . 
them, and potentially develop feelings of attraction. For example, Bongani says:

Someone who would greet me for instance, they would first mention my chair for some reason. Maybe they'll say: "that looks nice", or "is it expensive", or anything along those lines. Or, some sort of joke: "can I have a lift?" While maybe it's an innocent icebreaker, if you will, it does almost show that that is what they saw first and they decided to comment on that first, as opposed to saying, "hey", for instance. So to me that reflects that that is what they saw first, which, to me, it's almost like the disability comes before the person.

Similarly, Simon, a man in his 30s, talked about representing his disability in online dating:

...once or twice that I [tried online dating], I'm not going to put a picture up there of my face or just face and shoulders - I put a picture up there of who I am. So I'll put a picture of my wheelchair on the beach or whatever. And I must say, from that I've had very little returns or replies. So I think the first thing people see is the chair, they don't see the person.

There may also be some beliefs, which our participants described as being part of the culture with which they identified, that discourage people without disability from dating or being in relationships with people who have physical disabilities. For example, Sifiso, a young man, spoke about how some people may believe him to be bewitched. He says:

In our society, when you are sitting in a wheelchair, people think that you are bewitched. Now if you are bewitched, no one wants to come close to you. No one wants to be your friend. No one wants to be your family. No one wants to be close to you at all because you are going to curse them. The curse that you are under is going to affect them. So they don't want to come close to you. They don't want your help. Some believe that if they come across you and you say hello and you carry on with the conversation a little bit, you are planting that curse onto them. So if the situation is like that, then there is no way that you will have a friend in a society like that, not a girlfriend. A girlfriend is difficult to get while you are still walking, how if you are cursed? 
Naturally, there is not one single experience of being Xhosa, or of Xhosa culture; but Sifiso's experience of his own exclusion hinged on what he understood to be culturally determined ways of understanding physical disability.

Many of the participants spoke about how they felt unattractive and this was a barrier to meeting people, dating and having relationships, as they thought others saw them as unattractive. Typical statements from participants were:

I also didn't want to because I wasn't feeling attractive. I didn't feel attractive. For me, if I didn't have sex, it would have been fine. (Cleone)

Sometimes people are always judging and criticising those who don't look in a perfect manner for them. (Nico)

My friends, long time before me, for them it was easy to have boyfriends. But for me it was not easy, because nobody wants to have a girlfriend who looks like this. (Pride)

For some participants, like Tas, reclaiming a sense of attractiveness was important, not only for self-esteem, but in an attempt to challenge the perception of unattractiveness from the public:

I believe that people with a disability, we still need to look good when you dress up. You need to look good. You need to look neat and present yourself in a clean and neat manner. So for me, I feel as a person with a disability you still need to dress up and look attractive, especially when it comes to women. I still dress up. I still dress up to impress females. When a female sees me I believe that she needs to admire me when she looks at me, not just for being dressed up nicely, but also for my attitude as well. Because people generally have a mindset that people with disabilities are dirty, untidy and they don't really look good. So they have that kind of mindset that people with disabilities can't really dress up. When they see I've got a nice jacket on they will say, "ah, look at this jacket that you have on". So that also helps to change people's minds, that we still have a sense of style and we still want to look good and be accepted as normal people in society as well. (Tas; Image 2.2) 


\section{Concluding Notes and Take Home Points}

So, let us return to the initial question posed in this chapter: "How does a man or a woman who is paralysed and uses a wheelchair have sex"? As we have seen in this chapter, and more broadly in this book, it is certainly possible, and for most people with physical disabilities, as with most people without disability, their sexual needs, wishes and desires are very much part of who they are. While sex is often thought of as penetrative, it is, in reality, practiced and experienced in a variety of ways. Thus,

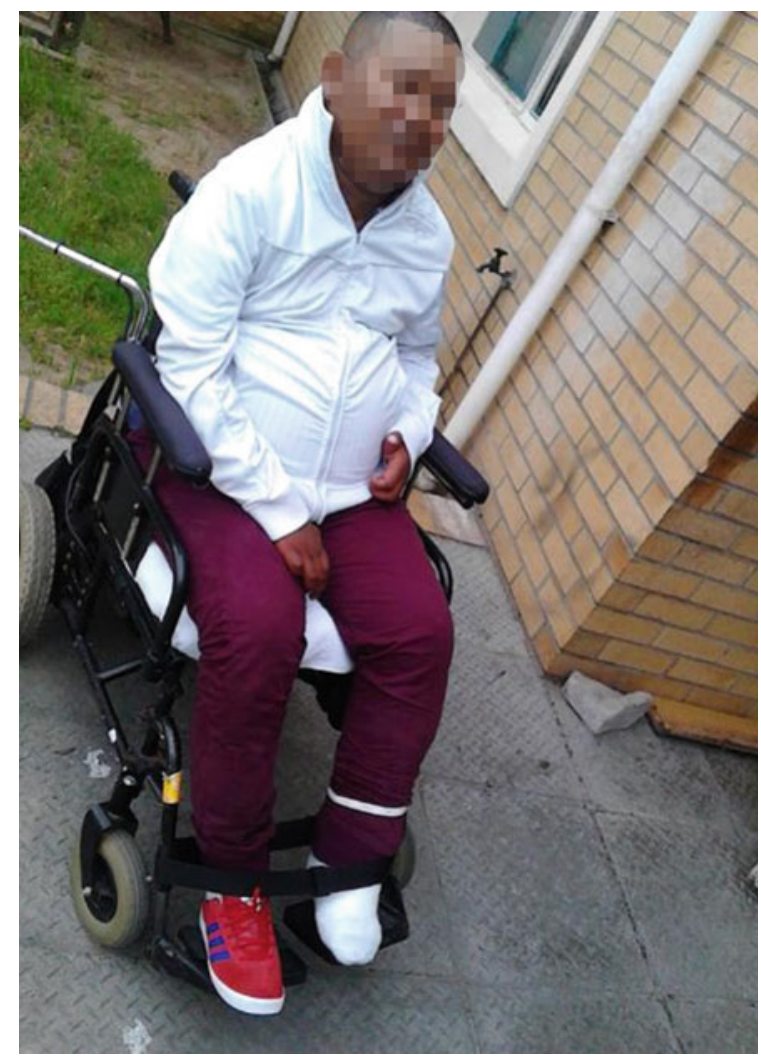

Image 2.2 Looking good (Photo by Tas) 
if penetrative expression is limited, there are still many ways of living out one's sexuality and to experience love and intimacy. However, as in many areas of the lives of people with physical disabilities, the attituedes of people without disabilities are influential, and can impact on the ability of people with physical disabilities to develop and express their sense of their sexuality.

\section{REFERENCES}

Brown, R. (2011). Prejudice: Its social psychology. Chichester: Wiley.

Carew, M. T., Braathen, S. H., Swartz, L., Hunt, X., \& Rohleder, P. (2017). The sexual lives of people with disabilities within low-and middle-income countries: A scoping study of studies published in English. Global Health Action, $10(1), 1337342$.

Carew, M. T., Braathen, S. H., Hunt, X., Swartz,. L., \& Rohleder, P. (2019). Predictors of negative beliefs toward the sexual rights and sexual healthcare of people with physical disabilities in South Africa. Disability and Rebabilitation, 1-9. https://doi.org/10.1080/09638288.2019.1608323.

Carew, M. T., et al. (2019). The impact of exposure to media coverage of the 2012 Paralympic Games on mixed physical ability interactions. Journal of Community \& Applied Social Psychology, 29(2), 104-120. https://doi.org/ $10.1002 /$ casp.2387.

Chirawu, P., Hanass-Hancock, J., Aderemi, T., Reus, L., \& Henken, A. (2014). Protect or enable? Teachers' beliefs and practices regarding provision of sexuality education to learners with disability in KwaZulu-Natal, South Africa. Sexuality and Disability, 32. https://doi.org/10.1007/s11195-014-9355-7.

Condrau, F. (2007). The patient's view meets the clinical gaze. Social History of Medicine, 20(3), 525-540. https://doi.org/10.1093/shm/hkm076.

Cuskelly, M., \& Gilmore, L. (2007). Attitudes to sexuality questionnaire (individuals with an intellectual disability): Scale development and community norms. Journal of Intellectual and Developmental Disability, 32(3), 214-221.

de Reus, L., Hanass-Hancock, J., Henken, S., \& Van Brakel, W. (2015). Challenges in providing HIV and sexuality education to learners with disabilities in South Africa: The voice of educators. Sex Education, 15, 1-15. https:// doi.org/10.1080/14681811.2015.1023283.

Fine, M., \& Asch, A. (2018). Disabled women: Sexism without the pedestal. In M. J. Deegan (Ed.), Women and disability-The double handicap (pp. 6-22). New York: Routledge.

Fiske, S. T., Cuddy, A. J. C., Glick, P., \& Xu, J. (2002). A model of (often mixed) stereotype content: Competence and warmth respectively follow from 
perceived status and competition. Journal of Personality and Social Psychology, 82(6), 878-902. https://doi.org/10.1037/0022-3514.82.6.878.

Garland-Thomson, R. (2009). Staring: How we look. New York: Oxford University Press.

Gilmore, L., \& Chambers, B. (2010). Intellectual disability and sexuality: Attitudes of disability support staff and leisure industry employees. Journal of Intellectual and Developmental Disability, 35(1), 22-28.

Goodley, D. (2016). Disability studies: An interdisciplinary introduction. London: Sage.

Goffman, E. (1997). Selections from stigma. In L. J. Davis (Ed.), The disability studies reader (pp. 203-215). New York: Routledge.

Hassouneh-Phillips, D., \& McNeff, E. (2005). "I thought I was less worthy": Low sexual and body esteem and increased vulnerability to intimate partner abuse in women with physical disabilities. Sexuality and Disability, 23(4), 227-240. https://doi.org/10.1007/s11195-005-8930-3.

Hunt, X., Swartz, L., Carew, M., Braathen, S. H., Chiwaula, M., \& Rohleder, P. (2017a). The sexual and reproductive rights and benefit derived from sexual and reproductive health services of people with physical disabilities in South Africa: Beliefs of non-disabled people. Reproductive Health Matters, 25(50). https://doi.org/10.1080/09688080.2017.1332949.

Hunt, X., Swartz, L., Carew, M. T., Braathen, S. H., Chiwaula, M., \& Rohleder, P. (2017b). Dating persons with physical disabilities: The perceptions of South Africans without disabilities. Culture, Health or Sexuality,. https://doi.org/ 10.1080/13691058.2017.1334964.

Hunt, X., Rohleder, P., Braathen, S. H., Swartz, L., \& Carew, M. (2018). Withdrawn, strong, kind, but de-gendered: Non-disabled South Africans' stereotypes concerning persons with physical disabilities. Disability \& Society. https://doi.org/10.1080/09687599.2018.1498768.

Marini, I., Chan, R., Feist, A., \& Flores-Torres, L. (2011). Student attitudes toward intimacy with persons who are wheelchair users. Rehabilitation Research, Policy, and Education, 25(1-2), 15-25.

Marini, I., Wang, X., Etzbach, C. A., \& Del Castillo, A. (2013). Ethnic, gender, and contact differences in intimacy attitudes toward wheelchair users. Rehabilitation Counseling Bulletin, 56(3), 135-145. https://doi.org/10.1177/003 4355212456605.

Milligan, M. S., \& Neufeldt, A. H. (2001). The myth of asexuality: A survey of social and empirical evidence. Sexuality and Disability, 19(2), 91-109.

Mueller-Johnson, K., Eisner, M. P., \& Obsuth, I. (2014). Sexual victimization of youth with a physical disability: An examination of prevalence rates, and risk and protective factors. Journal of Interpersonal Violence, 29(17), 3180-3206. https://doi.org/10.1177/0886260514534529. 
Nario-Redmond, M. R. (2010). Cultural stereotypes of disabled and nondisabled men and women: Consensus for global category representations and diagnostic domains. British Journal of Social Psychology, 49(3), 471-488.

Paluck, E., Green, S., \& Green, D. (2019). The contact hypothesis re-evaluated. Behavioural Public Policy, 3(2), 129-158. https://doi.org/10.1017/bpp.201 8.25 .

Park, D. C., \& Radford, J. P. (1998). From the case files: Reconstructing a history of involuntary sterilisation. Disability \& Society, 13(3), 317-342.

Rohleder, P., Braathen, S. H., \& Carew, M. T. (2018). Disability and sexual bealth: A critical exploration of key issues. London: Routledge.

Roy, M. (2010). A case note follow-up of women with intellectual disability referred for sterilization. Journal of Intellectual Disabilities, 14(1), 43-52.

Seidel, A., Wienholz, S., Michel, M., Luppa, M., \& Riedel-Heller, S. G. (2014). Sexual knowledge among adolescents with physical handicaps: A systematic review. Sexuality and Disability, 32(3), 429-441. https://doi.org/10.1007/ s11195-013-9326-4.

Tilley, E., Walmsley, J., Earle, S., \& Atkinson, D. (2012). 'The silence is roaring': Sterilization, reproductive rights and women with intellectual disabilities. Disability \& Society, 27(3), 413-426.

United Nations, U. (2006). Convention for the Rights of Persons with Disability (UNCRPD). Available at: https://www.un.org/development/desa/disabilit ies/convention-on-the-rights-of-persons-with-disabilities/convention-on-therights-of-persons-with-disabilities-2.html.

Vilchinsky, N., Werner, S., \& Findler, L. (2010). Gender and attitudes toward people using wheelchairs: A multidimensional perspective. Rebabilitation Counseling Bulletin, 53(3), 163-174.

WHO \& The World Bank. (2011). World report on disability. Geneva: WHO. Retrieved from: https://www.who.int/publications/i/item/worldreport-ondisability.

Wolfe, P. S. (1997). The influence of personal values on issues of sexuality and disability. Sexuality and Disability, 15(2), 69-90. 
Open Access This chapter is licensed under the terms of the Creative Commons Attribution 4.0 International License (http://creativecommons.org/licenses/ by $/ 4.0 /$ ), which permits use, sharing, adaptation, distribution and reproduction in any medium or format, as long as you give appropriate credit to the original author(s) and the source, provide a link to the Creative Commons license and indicate if changes were made.

The images or other third party material in this chapter are included in the chapter's Creative Commons license, unless indicated otherwise in a credit line to the material. If material is not included in the chapter's Creative Commons license and your intended use is not permitted by statutory regulation or exceeds the permitted use, you will need to obtain permission directly from the copyright holder.

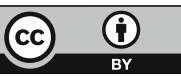

